\title{
Baroreflex Activation for the Treatment of Heart Failure
}

\author{
Hani N. Sabbah, Ph.D., FACC, FCCP, FAHA \\ Department of Medicine, Division of Cardiovascular Medicine, Henry Ford Hospital, Detroit, \\ Michigan
}

\begin{abstract}
Autonomic dysregulation is a feature of heart failure (HF) characterized by sustained increase of sympathetic drive and by withdrawal of parasympathetic activity. Both maladaptations are independent predictors of poor long-term outcome in patients with HF. Considerable evidence exists that supports the use of pharmacologic agents that partially inhibit sympathetic activity as an effective long-term therapy for patients with HF; the classic example being the use of selective and non-selective beta-adrenergic receptor blockers. In contrast, modulation of parasympathetic activation as potential therapy for HF has received only limited attention. This review discusses the results of recent pre-clinical animal studies that provide support for the possible use of baroreflex electrical stimulation, also know as baroreflex activation therapy (BAT), as a long-term therapeutic approach for the treatment of patients with chronic HF. In addition to exploring the effects of chronic BAT on left ventricular (LV) function and chamber remodeling, the review will also address the effects of long-term BAT on ventricular arrhythmias and on potential modifiers of the HF state that include maladaptations of both the nitric oxide and beta-adrenergic receptor signal transduction pathways. The results of the pre-clinical studies conducted to date have shown that in dogs with advanced HF, monotherapy with BAT improves global LV systolic and diastolic function and partially reverses LV remodeling both globally and at cellular and molecular levels. In addition BAT therapy was shown to markedly increase the threshold for lethal ventricular arrhythmias in dogs with chronic HF. These benefits of BAT support the continued exploration of this therapeutic modality for treating patients with chronic HF and those with increased risk of sudden cardiac death.
\end{abstract}

\section{Keywords}

Congestive heart failure; Animal models of human disease; Heart failure - basic studies; Baroreflex function; Ventricular Function; Ventricular dilation; mRNA expression; Ventricular arrhythmias; Electrophysiological testing; Plasma biomarkers; Sympathetic stimulation; Parasympathetic stimulation; Beta-adrenergic signaling; Nitric oxide; Inflammatory cytokines

\section{Introduction}

Autonomic dysfunction occurs in heart failure (HF) and is characterized by enhanced sympathetic activity and withdrawal of parasympathetic control. This autonomic imbalance has long been recognized as an important mediator of increased mortality and morbidity in myocardial infarction and HF $(1,2)$. Results from the Autonomic Tone and Reflexes after Myocardial Infarction Study (ATRAMI) and the Cardiac Insufficiency Bisoprolol Study II

\footnotetext{
Address for Correspondence: Hani N. Sabbah, PhD, Director, Cardiovascular Research, Henry Ford Hospital, 2799 West Grand Boulevard, Detroit, Michigan 48202, Office Phone: (313) 916-7360, Office Fax: (313) 916-3001, hsabbah1@ @hfhs.org.

Disclosures

Hani N. Sabbah has received grant funding from and was a consultant to CVRx, Inc.
} 
(CIBIS II) showed that diminished vagal activity and increased heart rate are predictors of high mortality in these patient populations $(3,4)$. The sustained increase of sympathetic drive along with reduced parasympathetic activity and activation of the renin-angiotensinaldosterone system (RAAS) in HF also contribute to progressive left ventricular (LV) dysfunction, progressive LV remodeling, end-organ damage and ultimately death (5-9). The mechanisms responsible for sustained sympathetic excitation in HF are not fully understood. It is generally believed that the arterial reflexes, including the carotid sinus baroreflex, that are normally inhibitory to this system, have reduced sensitivity in HF and, therefore, allow sympathetic outflow to proceed unchecked (10-14). Several studies have shown an abnormally depressed arterial baroreflex control in $\operatorname{HF}(11,13,15-20)$. This autonomic maladaptation in HF can lead to increased heart rate, dysregulation of key components of the cardiac beta-adrenergic receptor signal transduction pathway, dysregulation of nitric oxide (NO) signalling and the development of life threatening ventricular arrhythmias.

Studies in conscious resting normal dogs have shown that activation of the carotid sinus reflex through electrical stimulation can decrease heart rate and can also decrease sympathetic constrictor tone during exercise (21). Studies in patients have also shown that electrical stimulation of the carotid baroreflex can prolong the R-R interval secondary to augmented parasympathetic activity (22). The modulation of heart rate (HR) and sympathetic tone are, at present, recognized as important therapeutic targets in HF. Chronic carotid sinus nerve stimulation has also been shown to be effective in the reversal of systemic arterial hypertension (23) relief of angina pectoris (24), improvement in heart rate variability (25) and sympathetic inhibition (26). Numerous studies in experimental animal models of HF in which the long-term use of beta-blockers and other anti-adrenergic agents and more recently from use of specific and selective agents that reduce HR through inhibition of the cardiac pacemaker current $\mathrm{I} f$, have shown that these agents can prevent or attenuate progressive LV remodeling (27-30).

While much of the emphasis in treating HF over the past two decades has focused on modulation of sympathetic activity, considerable interest has emerged recently in modulating parasympathetic activity as a therapeutic target for treating chronic HF. It has long been recognized that alteration in cardiac vagal efferent activity through peripheral cardiac nerve stimulation can produce bradycardia $(31)$, and modification in atrial $(32,33)$ ventricular contractile function $(34,35)$. Electrical Vagus nerve stimulation (VNS) has been shown to prevent sudden cardiac death in conscious dogs with a healed myocardial infarction (36) and markedly improves long-term survival after chronic HF in rats $(37,38)$. We recently showed that long-term electrical baroreflex activation therapy (BAT) in dogs with chronic HF can improve LV systolic function and attenuate progressive LV remodeling (39). The discussion that follows will focus on the beneficial consequences of restoring autonomic balance in HF through the use of long-term BAT delivered using the Rheos System (CVRx, Inc., Minneapolis, MN). We will show that the reduction in sympathetic overdrive and augmentation of parasympathetic drive with long-term BAT in animals with experimental HF can reduce HR, improve adrenergic receptor and nitric oxide signaling, and markedly increase the threshold for lethal ventricular arrhythmias and, in doing so, improve global LV function and partially reverse LV chamber remodeling. The latter has been shown to correlate well with improved long-term mortality and morbidity in patients with chronic HF.

\section{BAT in Dogs with Coronary Microembolization-Induced HF}

\section{BAT Study Protocols in Dogs with Microembolization-Induced HF}

Two separate studies were conducted in which the Rheos System (CVRx, Inc., Minneapolis, $\mathrm{MN}$ ) was used to deliver BAT in dogs with microembolization-induced HF $(40,41)$. In the 
first study dedicated primarily to hemodynamic and ventriculographic assessment of LV function and remodeling, 14 dogs with a LV ejection fraction of approximately $25 \%$ were studied. Eight dogs were randomized to active BAT (Rheos System ON) and 6 to no therapy at all (Sham-operated control, Rheos System OFF). All dogs were followed for 3 months. In the second study, dedicated primarily to electrophysiologic testing for the induction of arrhythmias, 14 dogs also with LV ejection fraction $~ 25 \%$ were studied. Seven dogs were randomized to active BAT (Rheos System ON) and 7 to no therapy at all (Sham-operated control, Rheos System OFF). In this study all dogs were followed for 6 months. In both studies, the Rheos system implant procedure and BAT stimulation were carried out as previously described $(14,40)$. Briefly, stimulating electrodes were implanted circumferentially around both carotid sinuses and connected to the implantable pulse generator. Efficacy of the stimulation algorithm and proper placement of the electrodes were confirmed at the time of surgery by 3 to 4 acute stimulation runs performed 3-5 minutes apart and each confirming an acute drop of blood pressure and a reduction of heart rate. Dogs assigned to the BAT treatment group received a predetermined voltage with $0.5 \mathrm{msec}$ square wave pulses at $50-100 \mathrm{~Hz}$ at a duty cycle of 9 minutes $\mathrm{ON}$ and one minute OFF (39).

\section{Effects of BAT on HR Assessed from Ambulatory ECG Holter Monitoring}

The effects of long-term treatment with BAT on HR and ventricular arrhythmias were evaluated in dogs with coronary microembolization-induced HF using 24 hour ambulatory ECG Holter monitoring (39). In sham-operated control dogs, maximum HR increased from $119 \pm 40$ to $158 \pm 32$ beats/min, average HR increased from $69 \pm 22$ to $76 \pm 15$ beats $/ \mathrm{min}$ and minimum HR increased from $39 \pm 11$ to $45 \pm 11$ beats/min during a 3 month follow-up period. In BAT-treated dogs, maximum HR decreased from $161 \pm 40$ to $122 \pm 47$ beats/min, average HR decreased from $92 \pm 19$ to $64 \pm 18$ beats/min and minimum HR decreased from $54 \pm 18$ to $38 \pm 11$ beats/min (39). Even though none of these HR changes reached statistical significance, the trends support the premise that BAT reduces HR in the setting of HF (39).

\section{Effects of Long-term Treatment with BAT on LV Function and Remodeling in Dogs with Microembolization-Induced HF}

In dogs with advanced HF, long-term treatment with BAT significantly increased LV ejection and stroke volume compared to untreated sham-operated controls (Fig. 1) (39). The increase in ejection fraction was associated an increase of both stroke volume and cardiac output suggesting a clear improvement of LV systolic function. Long-term treatment with BAT also improved indexes of LV diastolic function as evidenced by a significant increase in early mitral inflow deceleration time (DT), a decrease of LV end-diastolic pressure, an increase in the ratio between peak mitral flow velocity in early diastole to peak mitral inflow velocity during left atrial contraction (PE/PA), and a decrease in LV end-diastolic circumferential wall stress (Fig. 1) (39). The change in these diastolic indexes with BAT support the premise that BAT may also improve LV diastolic function in addition to improving LV systolic function. Long-term treatment with BAT significantly decreased LV end-systolic and end-diastolic volumes suggesting that this form of therapy can have a beneficial effect on reducing LV size (Fig. 1). BAT also improved indices of LV shape (39) and significantly reduced functional mitral regurgitation (37). The reduction in LV size, the restoration of ellipsoidal LV shape and the reduction in the severity of functional mitral regurgitation suggest that this form of chronic therapy can reverse, albeit partially, the structural changes that drive pathologic LV remodeling.

\section{Effects of BAT on Cellular Measures of LV Remodeling}

In dogs with coronary microembolization-induced HF, long-term treatment with BAT elicits important changes in cellular and structural markers of LV remodeling. Histomorphometric assessment performed at the end of 3 months of follow-up showed that compared to control, 
treatment with BAT resulted in nearly $40 \%$ reduction in the volume fraction of replacement fibrosis (39). This observation suggests that ongoing cardiomyocyte loss and hence their replacement by fibrous tissue may be prevented or attenuated when long-term therapy with BAT is implemented. Treatment with BAT was also associated with a near $22 \%$ reduction in reactive interstitial fibrosis, a finding that can lead to improved LV relaxation and LV compliance and hence LV filling. Heart failure is also accompanied by a reduction in myocardial capillary to fiber ratio and by an increase in the oxygen diffusion distance (half the distance between 2 adjoining capillaries) that can lead to hypoxia of the failing myocardium (43). Studies in dogs with HF showed that long-term treatment with BAT is associated with near normalization of capillary density and a near $16 \%$ reduction in oxygen diffusion distance (43). Finally, long-term treatment with BAT was associated with a near $24 \%$ reduction in cardiomyocyte cross-sectional area, a measure of cardiomyocyte hypertrophy (43). These data suggest that BAT can attenuate pathologic hypertrophy and in doing so, restore a near normal LV mass that is in-line with available blood supply.

\section{Effects of BAT on Cardiac Beta-Adrenergic Signal Transduction Pathway}

In dogs with coronary microembolization-induced chronic HF, long-term treatment with BAT resulted in partial normalization of components of the cardiac beta-adrenergic signaling pathway (Fig. 2) (39). Compared to LV myocardium of sham-operated control dogs, the LV myocardium of dogs treated with BAT showed up-regulation of mRNA expression of $\beta 1$-adrenergic receptors with no change in the expression of $\beta 2$-adrenergic receptors. BAT-treated dogs also showed up-regulation of mRNA expression of adenylyl cyclase and down-regulation of $\beta$-adrenergic receptor kinase. These improvements at the molecular level were accompanied by a significant reduction in circulating plasma norepinephrine levels (39). Long-term treatment with BAT also resulted in down regulation of angiotensinogen, leading to a possible partial de-activation of the vasoconstrictive influence of tissue RAAS (39). These findings suggest that delivery of BAT in dogs with HF may restore sensitivity of the failing myocardium to adrenergic stimulation while attenuating the detrimental action of RAAS-induced vasoconstriction.

\section{Effects of BAT on Isoforms of Nitric Oxide Synthase}

The effects of long-term treatment with BAT on the nitric oxide synthases (NOS) were also examined in dogs with microembolization-induced HF (38). Nitric oxide (NO) is formed from the guanidine group of L-arginine in an NADPH-dependent reaction catalyzed by a family of NOS enzymes namely, endothelin NOS (eNOS), inducible NOS (iNOS) and neuronal NOS (nNOS). It is well known that NO produced by eNOS plays an important role in the regulation of cell growth, programmed cell death and vasodilation (44). Nitric oxide produced from eNOS from cardiomyocytes can enhance myocardial relaxation and regulate contractility as well as coronary perfusion $(45,46)$. In dogs with coronary microembolization-induced HF, mRNA and protein expression of eNOS in LV myocardium is significantly down-regulated compared to normal dogs (47). Long-term treatment with BAT significantly improves mRNA expression of eNOS (Fig. 2) (39).

Inducible NOS is expressed by many different cell types including cardiomyocytes and is up-regulated in HF (46). Increased expression of iNOS can lead to apoptosis (48) and can result in peroxynitrite generation associated with fibrosis, LV hypertrophy, chamber dilation and a cardiomyopathic phenotype (49). Increased expression of iNOS has also been shown to be associated with increased incidence of heart block and of sudden cardiac death (49). In dogs with coronary microembolization-induced HF, mRNA and protein expression of iNOS in LV myocardium is significantly up-regulated compared to normal dogs (47). Long-term treatment with BAT has been shown to normalize mRNA expression of iNOS in the failing dog LV myocardium (Fig. 2) (39). 
Recent studies have suggested that the neuronal form of NOS or nNOS is present in cardiomyocytes (50) and may be associated with the ryanodine receptor calcium release channel in the sarcoplasmic reticulum (51) and, therefore, may act to influence calcium cycling and contractility (51). nNOS is up-regulated in myocardium of rats with myocardial infarctions and in human failing hearts (52). In rats with HF, preferential inhibition of nNOS leads to increased sensitivity of the myocardium to beta-adrenergic stimulation; a finding consistent with the concept that nNOS-derived NO production may play a role in the autocrine regulation of myocardial contractility (53). In dogs with coronary microembolization-induced HF, mRNA and protein expression of nNOS in LV myocardium is significantly up-regulated compared to normal dogs (47). Long-term treatment with BAT was shown to normalize mRNA expression of iNOS in the failing dog LV myocardium (Fig. 2) (39).

The observation of normal physiologic balance between NOS isoforms suggest that increased elaboration of NO occurs following treatment with BAT. It is difficult to directly assess the level of NO due to its very short half life in the body. Measurements of the levels of NO metabolites, specifically the pool of nitrate and nitrite, are often used as a reflection of changes levels of NO. In the failing LV myocardium, the level of these metabolites of NO is significantly lower than in normal myocardium. Long-term treatment with BAT in dogs with HF increase in the total pool of nitrate and nitrite in LV myocardium, thus supporting the concept that restoration of autonomic balance in $\mathrm{HF}$ elicits normalization of physiologic NO synthesis and elaboration.

\section{Effects of BAT on Outcomes of Electrophysiologic Testing}

A characteristic of patients with HF is the high incidence of malignant ventricular arrhythmias that frequently culminate in sudden cardiac death. Patients with HF in whom these lethal arrhythmias can be induced by electrophysiological (EP) testing carry a high risk of sudden cardiac death. The effect of long-term treatment with BAT on EP-induced ventricular arrhythmias was also evaluated in dogs with microembolization-induced HF described earlier. EP testing was conducted at baseline prior to therapy and after 3 and 6 months of treatment with BAT ( $n=7$ ) or no treatment at all (control $n=7)$. Programmed ventricular stimulation was performed from the right ventricular apex and included delivery of up to 4 extrastimuli at progressively shorter coupling intervals (in steps of $10 \mathrm{msec}$ ). The extrastimuli were delivered following 8 ventricular paced beats with a drive cycle length between 600 and $200 \mathrm{msec}$. If a sustained monomorphic ventricular tachycardia (VT) or ventricular fibrillation (VF) could not be induced, then isoproterenol infusion was initiated to increase the sinus rate by $\sim 30 \%$ and the EP stimulation protocol was repeated (Fig. 3) (54). At baseline, a sustained VT or VF was induced in all 14 dogs (100\%). After 3 and 6 months of follow-up, all control dogs (100\%) were induced into sustained VT or VF. After 3 months of BAT, only 3 of 7 dogs (43\%) were induced into sustained VT or VF. After 6 months of BAT, only 2 of 7 dogs (29\%) were induced into sustained VT or VF (Fig. 3). In addition to these findings, the arrhythmia resistance index, a measure of the severity of stimulation needed to elicit VT or VF was significantly higher in BAT-treated dogs at 3 months and at 6 months in comparison to controls. Finally, 6 weeks after withdrawal of BAT (stimulation OFF) all 7 dogs assigned to the BAT group (100\%) were again induced into sustained VT or VF and the arrhythmia resistance index was returned to levels seen before initiating BAT (Fig. 3). These results suggest that monotherapy with BAT markedly increases the threshold for lethal ventricular arrhythmias in dogs with chronic HF. This benefit of BAT supports the continued exploration of this device as a therapeutic modality for treating patients with chronic HF and increased risk of sudden cardiac death. 


\section{BAT in Dogs with Rapid Pacing-Induced HF}

The long-term effects of treatment with BAT were also examined in dogs with pacinginduced HF (14). BAT electrode implantation was similar to that described earlier for dogs with microembolization-induced HF. Of a total of 15 dogs studied, 7 received BAT and 8 were assigned to control and did not receive BAT. Treatment with BAT was initiated 2 weeks after initiation of right ventricular pacing at 250 beats/min and all animals were followed for up to 12 weeks. In this study, there was no difference in LV ejection fraction or LV fractional area of shortening between treated dogs and controls. Treatment with BAT, however, significantly lowered LV end-diastolic pressure. In addition, survival was significantly greater for dogs undergoing BAT compared to control dogs $(68.1 \pm 7.4$ versus $37.3 \pm .2$ days) (14). This improvement in survival in BAT-treated dogs was associated with significantly lower plasma levels of plasma norepinephrine and angiotensin-II (14). It was speculated that the beneficial effects of BAT on survival in this animal model of HF may have been due, in part, to favorable modulation of sympathetic overdrive and excess activation of the RAAS (14).

\section{Conclusions and Clinical Implications}

A considerable body of pre-clinical and clinical investigations exists that supports the benefits of reducing sympathetic drive and enhancing parasympathetic drive in the management of patients with HF. Beta-blockers as well as other drugs that selectively lower heart rate such as ivabradine, an inhibitor of the I $f$ current, are examples of pharmacologic interventions that favorably modulate sympathetic and parasympathetic drive in patients with $\mathrm{HF}$ and, in doing so, improve long-term outcome. In recent years, we have experienced an emergence of devices that also target autonomic imbalance in HF. These include electrical cervical Vagus nerve stimulators, spinal cord stimulators, and electrical baroreflex activators as described in this review. In animals with experimental HF, long-term BAT improves LV systolic and diastolic function and partially reverses LV remodeling. BAT normalizes mRNA expression of key components of the $\beta$-adrenergic signal transduction pathway. Reversal of this maladaptive gene expression is likely to restore sensitivity of the failing myocardium to catecholamines and explains, in part, the improvement of LV function seen following chronic BAT. BAT also normalizes mRNA expression of eNOS, nNOS and iNOS in LV myocardium of dogs with HF. This finding provides additional insights into the possible mechanisms of action of this form of therapy. In addition to improving LV function, long-term monotherapy with BAT markedly increases the threshold for lethal ventricular arrhythmias in dogs with chronic HF and prolongs survival in dogs with pacing-induced HF. These benefits of BAT strongly support the continued exploration of this therapeutic modality for the treatment of patients with chronic HF and increased risk of sudden cardiac death. Clinical trials employing the recently-introduced, second generation CVRx Barostim neo (CVRx, Inc.) are currently underway to evaluate the safety and efficacy of BAT therapy for the treatment of patients with HF.

\section{Acknowledgments}

Funding Sources

Supported, in part, by research grants from CVRx, Inc. and National Heart, Lung, and Blood Institute PO1 HL074237-07 


\section{References}

1. Schwartz PJ, Vanoli E, Stramba-Badiale M, De Ferrari GM, Billman GE, Foreman RD. Autonomic mechanisms and sudden death. New insights from the analysis of baroreceptor reflexes in conscious dogs with and without myocardial infarction. Circulation. 1988; 78:969-973. [PubMed: 3168199]

2. Mortara A, La Rovere MT, Pinna GD, Prpa A, Maestri R, Febo O, Pozzoli M, Opasich C, Tavazzi L. Arterial baroreflex modulation of heart rate in chronic heart failure: clinical and hemodynamic correlates and prognostic implications. Circulation. 1997; 96:3450-3458. [PubMed: 9396441]

3. La Rovere MT, Bigger JT, Marcus FI, Mortara A, Schwartz PJ. Baroreflex sensitivity and heart-rate variability in prediction of total cardiac mortality after myocardial infarction. Lancet. 1998; 351:478-484. [PubMed: 9482439]

4. Lechat P, Hulot JS, Escolano S, Mallet A, Leizorovicz A, Werhlen-Grandjean M, Pochmalicki G, Dargie H, CIBIS II Investigators. Heart rate and cardiac rhythm relationships with bisoprolol benefit in chronic heart failure in CIBIS II trial. Circulation. 2001; 103:1428-1433. [PubMed: 11245648]

5. Packer M. Neurohumoral interactions and adaptations in congestive heart failure. Circulation. 1988; 77:721-730. [PubMed: 3280156]

6. Levine TB, Francis GS, Goldsmith SR, Simon AB, Cohn JN. Activity of the sympathetic nervous system assessed by plasma hormone levels and their relation to hemodynamic abnormalities in congestive heart failure. Am J Cardiol. 1982; 49:1659-1666. [PubMed: 7044086]

7. Swedberg K. Is neurohormonal activation deleterious to long-term outcome of patients with congestive heart failure? Protagonist's viewpoint. J Am Coll Cardiol. 1988; 62:3A-8A.

8. Packer M. Beta-blockade in heart failure. Basic concepts and clinical results. Am J Hypertension. 1998; 11:23S-37S.

9. Brunner-La Rocca HP, Esler MD, Jennings GL, Kaye DM. Effects of cardiac sympathetic nervous activity on mode of death in congestive heart failure. Eur Heart J. 2001; 22:1136-1143. [PubMed: 11428854]

10. Ferguson DW, Berg WJ, Sanders JS. Clinical and hemodynamic correlates of sympathetic nerve activity in normal humans and patients with heart failure: evidence from direct microneurographic recordings. J Am Coll Cardiol. 1990; 16:1125-1134. [PubMed: 2229759]

11. Eckberg DL, Drabinsky M, Braunwald E. Defective cardiac parasympathetic control in patients with heart failure. N Engl J Med. 1971; 285:877-883. [PubMed: 4398792]

12. Wang W, Chen J-S, Zucker IH. Carotid sinus baroreflex in dogs with experimental heart failure. Circ Res. 1991; 68:1294-1301. [PubMed: 2018993]

13. Creager MA. Baroreceptor reflex function in congestive heart failure. Am J Cardiol. 1992; 69:10G-16G. [PubMed: 1729856]

14. Zucker IH, Hackley JF, Cornish KG, Hiser BA, Anderson NR, Kieval R, Irwin ED, Sedar DJ, Peuler JD, Rossing MA. Chronic baroreceptor activation enhances survival in dogs with pacinginduced heart failure. Hypertension. 2007; 50:904-910. [PubMed: 17846349]

15. Zucker IH, Wang W, Brandle M, Schultz HD, Patel KP. Neural regulation of sympathetic nerve activity in heart failure. Prog Cardiovas Dis. 1995; 37:397-414.

16. Iellamo F, Sala-Mercado JA, Ichinose M, Hammond RJ, Pallante M, Ichinose T, Stephenson LW, O'Leary DS. Spontaneous baroreflex control of heart rate during exercise and muscle metaboreflex activation in heart failure. Am J Physiol. 2007; 293:H1929-H19376.

17. Kinugawa T, Dibner-Dunlap ME, Sica DA, Thames MD. Treatment with enalapril fails to prevent impaired cardiopulmonary baroreflex control in dogs with left ventricular dysfunction. J Card Failure. 1995; 1:381-389.

18. Ferguson DW. Digitalis and neurohormonal abnormalities in heart failure and implications for therapy. Am J Cardiol. 1992; 69:24G-33G.

19. Quest JA, Gillis RA. Effect of digitalis on carotid sinus baroreceptor activity. Circ Res. 1974; 357:247-255.

20. Wang W, Chen J-S, Zucker IH. Postexcitatory depression of baroreceptors in dogs with experimental heart failure. Am J Physiol. 1991; 260:H1160-H1165. [PubMed: 1849369] 
21. Vatner SF, Franklin D, Van Citters RL, Braunwald E. Effects of carotid sinus nerve stimulation on blood-flow distribution in conscious dogs at rest and during exercise. Circ Res. 1970; 27:495-503. [PubMed: 5507026]

22. Eckberg DL, Fletcher GF, Braunwald E. Mechanism of prolongation of the R-R interval with electrical stimulation of the carotid sinus nerve in man. Circ Res. 1972; 30:131-138. [PubMed: 4399972]

23. Schwartz SI, Griffith LSC, Neistadt A, Hagfors N. Chronic carotid sinus nerve stimulation in the treatment of essential hypertension. Am J Surg. 1967; 114:5-15. [PubMed: 6026450]

24. Braunwald E, Epstein SE, Glick G, Wechsler AS, Braunwald NS. Relief of angina pectoris by electrical stimulation of the carotid-sinus nerves. N Engl J Med. 1967; 277:1278-1283. [PubMed: 5299662]

25*. Wustmann K, Kucera JP, Scheffers I, Mohaupt M, Kroon AA, de Leeuw PW, Schmidli J, Allemann Y, Delacretaz E. Effects of chronic baroreceptor stimulation on the autonomic cardiovascular regulation in patients with drug-resistant hypertension. Hypertension. 2009; 54:530-536. [PubMed: 19620513]

26*. Heusser K, Tank J, Engeli S, Diedrich A, Menne J, Eckert S, Peters T, Sweep FCGJ, Haller H, Pichlmaier AM, Luft FC, Jordan J. Carotid baroreceptor stimulation, sympathetic activity, baroreflex function, and blood pressure in hypertensive patients. Hypertension. 2010; 55:619626. [PubMed: 20101001]

27. Sabbah HN, Shimoyama H, Kono T, Gupta RS, Sharov VG, Scicli G, Levine TB, Goldstein S. Effects of long-term monotherapy with enalapril, metoprolol and digoxin on the progression of left ventricular dysfunction and dilation in dogs with reduced ejection fraction. Circulation. 1994; 89:2852-2859. [PubMed: 8205701]

28. Sabbah HN, Stanley WC, Sharov VG, Mishima T, Tanimura M, Benedict CR, Hegde S, Goldstein S. Effects of dopamine $\beta$-hydroxylase inhibition with nepicastat on the progression of left ventricular dysfunction and remodeling in dogs with chronic heart failure. Circulation. 2000; 102:1990-1995. [PubMed: 11034950]

29. Morita H, Suzuki G, Chaudhry PA, Anagnostopoulos PV, Tanhehco EJ, Sharov VG, Goldstein S, Sabbah HN. Effects of long-term monotherapy with metoprolol CR/XL on the progression of left ventricular dysfunction and remodeling in dogs with chronic heart failure. Cardiovasc Drugs and Therapy. 2002; 16:433-449.

30. Sabbah HN, Wang M, Jiang A, Ilsar I, Gupta RC, Rastogi S. Long-term Monotherapy with Ivabradine Improves Left Ventricular Function and Prevents Progressive Chamber Remodeling in Dogs with Moderate Heart Failure (Abstract). Circulation. 2009; 120:S867.

31. Kunze DL. Reflex discharge patterns of cardiac vagal efferent fibers. J Physiol (Lond). 1972; 222:1-8. [PubMed: 4338691]

32. Harman MA, Reeves TJ. Effects of efferent nerve stimulation on atrial and ventricular function. Am J Physiol. 1968; 215:1210-1217. [PubMed: 5687515]

33. Wiggers CJ. Physiology of the mammalian auricles: II. Influence of the vagus nerves on the fractionate contraction of the right auricle. Am J Physiol. 1916:133-140.

34. DeGeest H, Levy M, Zieske H, Lipman RI. Depression on ventricular contractility by stimulation of the vagus nerves. Circ Res. 1965; 17:222-235. [PubMed: 14338695]

35. Henry, JP.; Meehan, JP. Circulation: Integrative physiology study. Year Book Medical Publishers; Chicago: 1971. p. 57

36. Vanoli E, De Ferrari GM, Stramba-Badiale M, Hull SS Jr, Foreman RD, Schwartz PJ. Vagal stimulation and prevention of sudden death in conscious dogs with healed myocardial infarction. Circ Res. 1991; 68:1471-1481. [PubMed: 2019002]

37. Li M, Zheng C, Sato T, Kawada T, Sugimachi N, Sunagawa K. Vagal nerve stimulation markedly improves long-term survival after chronic heart failure in rats. Circulation. 2004; 109:120-124. [PubMed: 14662714]

38. Zheng C, Li M, Inagaki M, Kawada T, Sunagawa K, Sugimachi M. Vagal stimulation markedly suppresses arrhythmias in conscious rats with chronic heart failure after myocardial infarction. Conf. Proc IEEE Eng Med Biol Soc. 2005; 7:7072-7075. [PubMed: 17281904] 
39**. Sabbah HN, Gupta RC, Imai M, Irwin ED, Rastogi S, Rossing MA, Kieval RS. Chronic Electrical Stimulation of the Carotid Sinus Baroreflex Improves LV Function and Promotes Reversal of Ventricular Remodeling in Dogs with Advanced Heart Failure. Circ Heart Fail. 2011; 4:65-70. [PubMed: 21097604]

40. Sabbah HN, Stein PD, Kono T, Gheorghiade M, Levine TB, Jafri S, Hawkins ET, Goldstein S. A canine model of chronic heart failure produced by multiple sequential coronary microembolizations. Am J Physiol. 1991; 260:H1379-1384. [PubMed: 1826414]

41. Sabbah HN, Shimoyama H, Kono T, Gupta RS, Sharov VG, Scicli G, Levine TB, Goldstein S. Effects of long-term monotherapy with enalapril, metoprolol and digoxin on the progression of left ventricular dysfunction and dilation in dogs with reduced ejection fraction. Circulation. 1994; 89:2852-2859. [PubMed: 8205701]

42. Lohmeier TE, Irwin ED, Rossing MA, Serdar DJ, Kieval RS. Prolongs activation of baroreflex produces sustained hypotension. Hypertension. 2004; 43:306-311. [PubMed: 14707159]

43. Sabbah HN, Sharov VG, Lesch M, Goldstein S. Progression of heart failure: A role for interstitial fibrosis. Mol. Cell Biochem. 1995; 147:29-34. [PubMed: 7494551]

44. Feng Q, Song W, Lu X, Hamilton JA, Lei M, Peng T, Yee S-P. Development of Heart Failure and congenital septal defects in mice lacking endothelial nitric oxide synthase. Circulation. 2002; 106:873-879. [PubMed: 12176963]

45. Kelly RA, Balligand JL, Smith TW. Nitric oxide and cardiac function. Circ Res. 1996; 79:363380. [PubMed: 8781470]

46. Paulus WJ, Shah AM. NO and cardiac diastolic function. Cardiovasc Res. 1999; 43:595-606. [PubMed: 10690331]

47. Gupta RC, Mishra S, Rastogi S, Imai M, Zaca V, Sabbah HN. Chronic therapy with electric Vagus Nerve stimulation normalizes mRNA and protein expression of nitric oxide synthase in myocardium of dogs with heart failure (Abstract). Europ Heart J. 2006; 27:477.

48. Pattern RD, DeNofrio D, El-Zaru M, Kakkar R, Saunders J, Celestin F, Warner K, Rastegar H, Khabbaz KR, Udelson JE, Konstam MA, Karas RH. Ventricular assist device therapy normalizes inducible nitric oxide synthase expression and reduces cardiomyocyte apoptosis in the failing human heart. J Am Coll Cardiol. 2005; 45:1419-1424. [PubMed: 15862412]

49. Mungrue IN, Gros R, You X, Pirani A, Azad A, Csont T, Schulz R, Butany J, Stewart DJ, Husain M. Cardiomyocyte overexpression of iNOS in mice results in peroxynitrite generation, heart block and sudden death. J Clin Invest. 2002; 109:735-743. [PubMed: 11901182]

50. Xu KY, Huso DL, Dawson TM, Bredt DS, Becker LC. Nitric oxide synthase in cardiac sarcoplasmic reticulum. Proc Natl Acad Sci USA. 1999; 96:657-662. [PubMed: 9892689]

51. Barouch LA, Harrison RW, Skaf MW, Rosas GO, Cappola TP, Kobeissi ZA, Hobai IA, Lemmon CA, Burnett AL, O’Rourke B, Rodriguez ER, Huang PL, Lima JA, Berkowitz DE, Hare JM. Nitric oxide regulates the heart by special confinement of nitric oxide synthase isoforms. Nature. 2002; 416:337-339. [PubMed: 11907582]

52. Damy T, Ratajczak P, Shah AM, Camors E, Marty I, Hasenfuss G, Marotte F, Samuel JL, Heymes C. Increased neuronal nitric oxide synthase-derived NO production in the failing human heart. Lancet. 2004; 363:1365-1367. [PubMed: 15110495]

53. Bendall JK, Damy T, Ratajczak P, Loyer X, Monceau V, Marty I, Milliez P, Robidel E, Marotte F, Samuel J-L, Heymes C. Role of myocardial neuronal nitric oxide synthase-derived nitric oxide in $\beta$-adrenergic hyporesponsiveness after myocardial infarction-induced heart failure in rat. Circulation. 2004; 110:2368-2375. [PubMed: 15466641]

54. Wang M, Zaca V, Jiang A, Ilsar I, Ebinger M, Sabbah MS, Dye K, Schuger C, Sabbah HN. Longterm baroreflex activation therapy increases the threshold for the induction of lethal ventricular arrhythmias in dogs with chronic advanced heart failure. Circulation. 2008; 118:S722. 

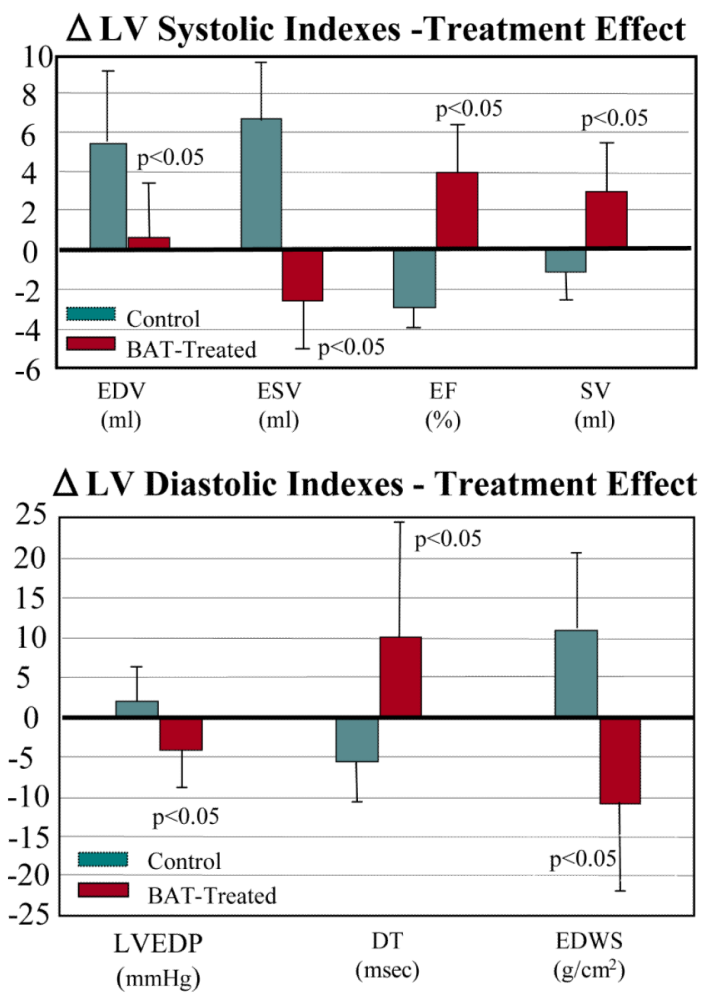

Fig. 1.

TOP: Treatment effect change $(\Delta)$ in left ventricular (LV) end-diastolic volume (EDV), endsystolic volume (ESV), ejection fraction (EF) and stroke volume (SV) in sham operated control dogs and dogs treated with baroreflex activation therapy (BAT). BOTTOM: Treatment effect change $(\Delta)$ in left ventricular (LV) end-diastolic pressure (EDP), deceleration time (DT) of early mitral valve inflow velocity, and end-diastolic circumferential wall stress (EDWS) in sham operated control dogs and dogs treated with baroreflex activation therapy (BAT). The figure is based on data contained in Reference 39. 
Beta-Adrenergic Receptor Signal Transduction Pathway
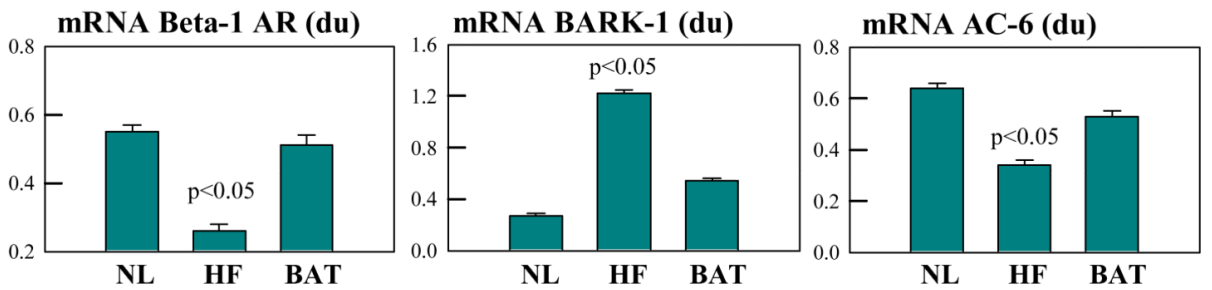

\section{Nitric Oxide Pathway}
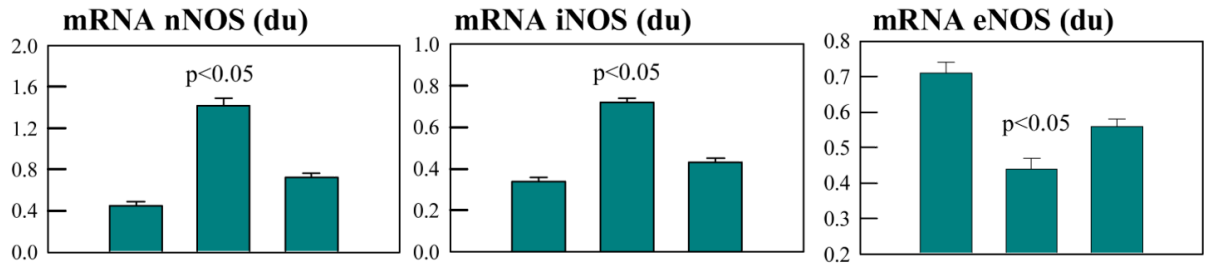

Fig. 2.

TOP: Bar graphs (mean \pm SEM) depicting differences in mRNA expression of beta-1 adrenergic receptors (AR), beta-adrenergic receptor kinase-1 (BARK-1) and adenylate cyclase-6 (AC-6) in left ventricular myocardium of normal (NL) dogs, dogs with heart failure (HF) that were not treated (controls) and dogs with HF treated with baroreflex activation therapy $(B A T) . d u=$ densitometric units. BOTTOM: Bar graphs (mean \pm SEM) depicting differences in mRNA expression of neuronal nitric oxide synthase (nNOS), inducible nitric oxide synthase (iNOS) and endothelial nitric oxide synthase (eNOS) in left ventricular myocardium of normal (NL) dogs, dogs with heart failure (HF) that were not treated (controls) and dogs with HF treated with baroreflex activation therapy (BAT). du = densitometric units. The figure is based on data contained in Reference 39. 


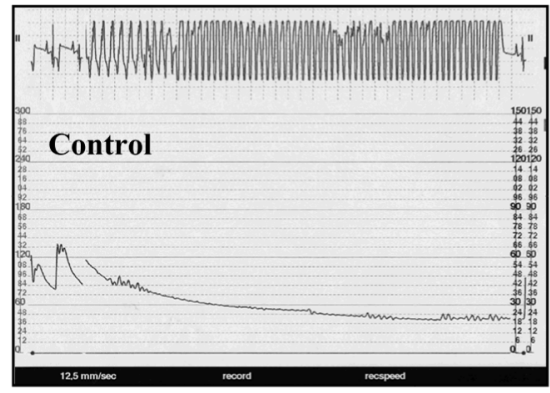

Percent of Dogs Induced into VT or VF

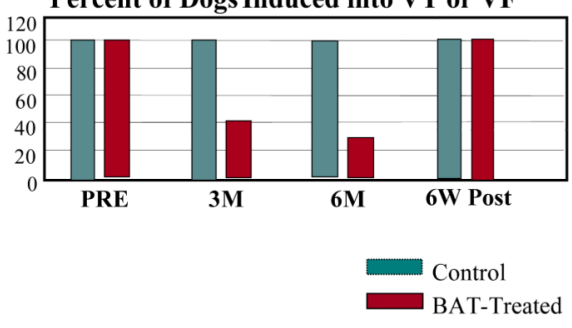

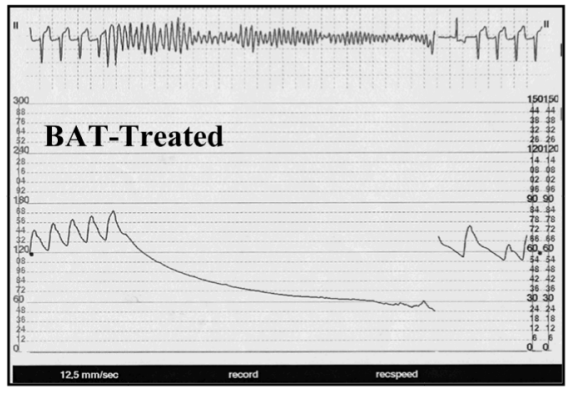

Effects of BAT on Arrhythmia Resistance in Experimental Heart Failure

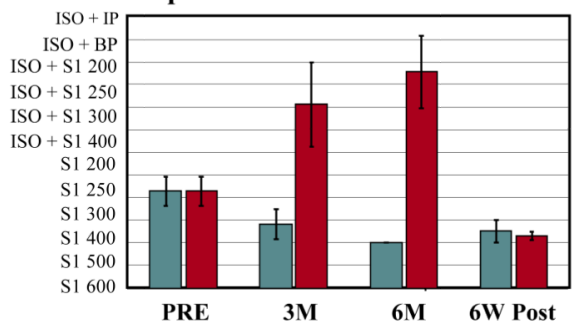

Fig. 3.

Top left: recording in an untreated control dog during an electrophysiological study showing the induction of a monomorphic ventricular tachycardia (VT) (upper tracing) associated with hemodynamic compromise depicted by fall in systemic arterial pressure (lower tracing) and requiring direct current (DC) cardioversion. Top right: recording in an BAT-treated dog during an electrophysiological study showing the induction of ventricular fibrillation (VF) (upper tracing) associated with hemodynamic compromise depicted by fall in systemic arterial pressure (lower tracing) and requiring direct current (DC) cardioversion. Lower left panel: bar graphs (mean) depicting the proportion of dogs in whom a VT or VF was induced at pre-treatment (PRE), 3 and 6 months (M) after initiating BAT-treatment or no treatment and at 6 weeks $(\mathrm{W})$ after withdrawal of BAT treatment ( 6 weeks starting at the end of 6 months of active treatment, POST). Lower right panel: Bar graphs (mean \pm SEM) depicting changes in the arrhythmias resistance index, a measure of the severity of the arrhythmiainducing protocol (least severe being S1 600 and most severe being ISO+IP), in control dogs and dogs treated with baroreflex activation therapy (BAT). Wk = weeks; ISO isoproterenol; IP = incremental pacing; $\mathrm{BP}=$ burst pacing. 